\title{
Risk Preferences and the Role of Emotions
}

\author{
By Anna Conte†, M. Vittoria Levatit and Chiara Nardi $\dagger$ \\ $\dagger$ University of Westminster \$University of Verona †Frankfurt School of Finance \& \\ Management
}

Final version received 11 July 2016.

\begin{abstract}
There is a large volume of research showing that emotions have relevant effects on decision-making. We contribute to this literature by experimentally investigating the impact of four specific emotional statesjoviality, sadness, fear and anger-on risk attitudes. In order to do so, we fit two models of behaviour under risk: the expected utility model and the rank dependent expected utility model, assuming several functional forms of the weighting function. Our results indicate that all emotional states mitigate risk aversion. Furthermore, we show that there are some differences across gender and participants' experience in laboratory experiments.
\end{abstract}

\section{INTRODUCTION}

Traditionally, economists tend to emphasize the role of rationality and to overlook that of emotions in the decision-making process. ${ }^{1}$ In the last two decades there has been a large volume of research showing that emotions do have relevant effects on decisionmaking. Loewenstein (2000) argues that emotions (or visceral factors, in his terminology) play a role in three different manifestations of an individual's life. In particular, emotions affect people's bargaining behaviour and their intertemporal choices (such as saving attitudes), and enter into their decision-making under risk and uncertainty. The latter is the object of investigation in the present work.

Loewenstein and Lerner (2003, p. 620) distinguish between expected emotions, which consist of 'predictions about the emotional consequences of decision outcomes', and immediate emotions, which are 'experienced at the time of decision making'. Even though we cannot rule out the possibility that expected emotions play a role, in this work we focus on immediate emotions and investigate whether temporary emotional states, experimentally induced by film clips, affect risk preferences.

Empirical research in psychology and, more recently, in economics has demonstrated that affect can somewhat influence individual risk preferences. Two conflicting theories can be distinguished in this research area. On the one hand, Isen and Patrick (1983) introduced the mood maintenance hypothesis $(\mathrm{MMH})$, which holds that positive affect induces risk-averse behaviour, while negative affect leads to risk-seeking behaviour. On the other hand, there is the affect infusion model (AIM), proposed by Forgas (1995), which suggests the exact opposite effects. Some authors (e.g. Kliger and Levy 2003; Zhao 2006) find empirical support for the MMH, while other scholars (e.g. Arkes et al. 1988; Yuen and Lee 2003; Chou et al. 2007; Grable and Roszkowski 2008) find evidence in favour of the AIM. There are also studies that end up with mixed results. Williams et al. (2003), for instance, show that while unhappy managers are significantly less riskseeking, happy managers are not more likely to seek risk. Drichoutis and Nayga (2013) report that both positive and negative moods increase risk aversion. Finally, in an experiment inducing joy, fear and sadness under non-existent, low and very high financial stakes, Treffers et al. (2012) find that, compared to a control group that did not receive any emotion manipulation, sadness leads to more risk aversion only if the financial stakes 
are non-existent or low; none of the induced affects influences risk preferences in the high-stake treatments.

The experimental study presented in this paper builds on this strand of literature. Yet our experimental design is novel in a number of important respects.

First, we consider discrete emotions, namely joviality, sadness, fear and anger. With some exceptions (such as Lerner and Keltner 2001; Kugler et al. 2012; Treffers et al. 2012; Guiso et al. 2013), most previous studies follow a valence-based approach to affects and contrast affective states of different valence, that is, 'positive' versus 'negative'. Grouping affects can generate perverse effects in that affective states of the same valence (e.g. sadness, fear and anger) may have conflicting influences on risk preferences, which can even cancel out one another (see, for example, Raghunathan and Pham 1999).

Second, we use salient monetary incentives, whereas most of the existing studies in this area provide small financial incentives (if any) to experimental subjects. ${ }^{2}$ In their review articles on the impact of financial incentives on choices, Camerer and Hogarth (1999) and Hertwig and Ortmann (2001) observe that incentives have the largest effect in individual decision-making studies. We can verify whether the documented impact of affect on risk attitudes will survive the introduction of salient monetary incentives.

Third, in contrast to all former experiments, we implement a within-subject design in the sense that we measure, and compare, individual risk preferences both before and after affective states are manipulated. This gives our study an important advantage because it prevents the confounding effect of heterogeneity in preferences to disturb the effect of emotions on willingness to take risk. ${ }^{3}$

A further important novelty of this paper lies in the way attitude to risk is measured. Specifically, we follow Hey (2001) and elicit risk preferences by presenting participants with 100 pairwise choice problems between two different lotteries. Previous economic studies measure risk preferences mainly looking at people's choices when faced with multiple price lists (MPLs). ${ }^{4}$ The main advantage of an MPL is that it is easy to explain to subjects and to implement. Additionally, it is incentive-compatible provided that only one decision is randomly selected for payment (Azrieli et al. 2012). However, an MPL has several disadvantages. For instance, Andersen et al. (2006) remark that it (i) elicits only interval responses rather than point ones, (ii) allows for multiple switching points, thus leading to potentially inconsistent decisions, and (iii) may be susceptible to framing effects. Recently, Bosch-Domènech and Silvestre (2013) find that MPLs suffer from 'embedding bias', that is, the removal of some pairs at the beginning and/or end of the list yields a decrease in risk aversion. ${ }^{5}$ These problems are overcome by the risk preferences elicitation method that we use here because such a method does not require a unique switching point, nor does it need point responses, to infer risk attitudes and to estimate parameters. Inconsistent behaviour can be described either by a given preference functional with some error or by a shifting preference functional (e.g. Hey 2001). Eliciting preferences through 100 pairwise choice questions enables us to collect several observations from each experimental subject and, consequently, to estimate precisely the participants' risk attitudes and how they vary, if at all, with the emotional state.

To our knowledge, this would be the first attempt to use a thorough experimental design - departing from past works in the ways outlined above-to study the impact of four specific emotional states on risk preferences. We use the same 100 choice problems as Hey (2001). These problems are performed twice-before and after the affect induction, so that the total number of problems faced by each subject is 200 . The four affective states (joviality, sadness, fear and anger) are induced using short film clips. ${ }^{6}$ 
Subjects participate either in one of the treatment groups (where the induction of only one of the four emotional states takes place) or in a control group (where a neutral affect film clip is shown). The inclusion of a control group enables us to be confident that the changes (if any) in risk preferences after the participants watched the film clip are a direct result of the emotion manipulation rather than changes attributable to potential confounding factors such as experimenter demand effects (Charness et al. 2012). We check the efficacy of the affect induction procedures using the Positive and Negative Affect Schedule (PANAS-X, Watson and Clark 1999; see Krohne et al. 1996 for a validated translation of the PANAS into German).

Previous literature shows that women are more risk-averse than men (see the surveys by Eckel and Grossman 2008; Croson and Gneezy 2009). Moreover, conventional wisdom and previous research from psychology indicate that women are more 'emotional' than men (e.g. Croson and Gneezy 2009, pp. 451-2 and references therein). Croson and Gneezy (2009) suggest that gender differences in risk attitudes may relate to differences in emotional reactions to risk. To date, however, little is known about the (potentially) different effects of emotions on male and female risk preferences (some noteworthy exceptions are Lerner et al. 2003; Fessler et al. 2004; Fehr-Duda et al. 2011). ${ }^{7}$ Herein, we use our experimental data to determine whether there are gender differences in the impact of joviality, sadness, fear and anger on risk preferences.

To further deepen the knowledge of the matter, we also explore whether there are differences in the effect of the four considered emotions on risk-taking depending on previous participation in laboratory experiments, which we call experience. While there is some evidence regarding how experience in one experiment may impact willingness to take risk in later experiments (e.g. Jamison et al. 2008; Chuang and Schechter 2015), to the best of our knowledge, nobody has investigated the impact of emotions on risk preferences distinguishing between experienced and inexperienced subjects. Levin et al. (1988) posit that previous experience in laboratory experiments may help people to focus more on the main part of the experiment (in our case, the lottery choice tasks), and to pay less attention to aspects that are peripheral to the decision task (in our case, emotions). Following this line of reasoning, one should expect the experienced subjects' risk attitudes to be less affected by emotions than the inexperienced subjects' risk attitudes. Our data, and the information stored in our database, enable us to assess whether or not this prediction is correct.

To estimate the role of joviality, sadness, fear and anger on risk-taking, and to determine whether there are differences according to gender and subjects' laboratory experience, we fit two preference functionals: the expected utility and the rank dependent expected utility, assuming several functional forms of the weighting function. We control for (i) heterogeneity between individuals by allowing the parameters of the model to vary between subjects, and (ii) heterogeneity within individuals (inconsistency of choices over repetitions) by means of a Fechnerian stochastic error term. Fitting different choice models of behaviour under risk using different functional forms serves us to identify (statistically) which of the fitted models is able to represent the data best. We adopt this approach because we want to avoid that misspecifications of the functional form bias the results.

When considering the entire sample, our results indicate that all the manipulated emotions lead to less risk-averse behaviour. We detect differences across gender: male risk preferences are influenced by sadness, while female risk propensity is affected by joviality. Both male and female risk attitudes are increased by fear. We find that past participation in experiments also matters in that joviality impacts on both the 
inexperienced and experienced participants' risk attitudes, whereas fear affects the inexperienced (but not the experienced) participants' risk attitudes. The influence of sadness and anger on risk attitudes, on the other hand, is found not to depend on the participants' experience.

The paper is organized as follows. Section I presents the experimental design and procedures. Section II describes the econometric model. Section III verifies if the emotion induction has been effective, and reports the results about the changes in risk attitudes. Section IV summarizes the main findings of the study and offers concluding remarks.

\section{EXPERIMENTAL DESIGN}

The experiment was programmed in z-Tree (Fischbacher 2007) and conducted in the experimental laboratory of the Max Planck Institute of Economics in Jena (Germany). The participants, undergraduate students from the Friedrich-Schiller University of Jena, were recruited using the ORSEE software (Greiner 2004).

The experiment was divided into two identical parts, separated by the emotion manipulation. Each part included a questionnaire about feelings, and the main experimental task aimed to measure the participants' risk attitudes. In what follows, we will first describe the methods that we used to elicit risk preferences, to induce emotions and to measure emotions. We will then report the full sequence of events that characterized the experiment.

\section{Methods}

Elicitation of risk preferences Risk attitudes were elicited using lotteries (as in Hey 2001). The subjects were presented with 100 pairwise choice problems between two different lotteries. They had to indicate whether they preferred the left-hand side lottery or the right-hand side lottery by pressing the corresponding button. ${ }^{8}$ Lotteries were presented as segmented circles on the computer screen. ${ }^{9}$

All the 100 problems involved probabilities that were multiples of one-eighth, and subjects were informed about this (the probabilities that we used are listed in Table 7 in Hey 2001). There were four possible outcomes: €0, €8, €16 and €24. These amounts were chosen to make the incentives offered by the main experimental task appropriate, given the time needed to complete it. Each lottery included at least one and at most three of these four outcomes.

Emotion induction We induced emotions by following procedures similar to those used in prior studies (e.g. Lerner et al. 2004; Gino and Schweitzer 2008). Participants were randomly assigned to one of five treatments - a joviality treatment, a sadness treatment, a fear treatment, an anger treatment or a neutral treatment - and were shown one of five different film clips (all tested on Germans by Hewig et al. 2005). Table 1 reports, for each treatment, the film from which the clip was taken and a short description of the clip watched by the participants. Each clip lasted less than 4 minutes.

Emotion measure To measure participants' emotions, we used the Positive and Negative Affect Schedule (PANAS-X, Watson and Clark 1999; validated German translation: Krohne et al. 1996). ${ }^{10}$ This psychometric scale contains 60 items, which describe different feelings and emotions. The 60 items can be compressed into two general (positive and negative affect), or eleven basic emotion scales. ${ }^{11}$ All the 60 different 
TABLE 1

Clips Shown to the Participants IN EACH TREATMENT

\begin{tabular}{|c|c|c|}
\hline Treatment & Film title & Description of the clip \\
\hline Joviality & When Harry met Sally & $\begin{array}{l}\text { Harry and Sally discuss whether Harry would notice } \\
\text { that a woman fakes an orgasm. }\end{array}$ \\
\hline Sadness & The Champ & $\begin{array}{l}\text { A boxer is lying severely injured on a table when his } \\
\text { son enters and sees him dying. }\end{array}$ \\
\hline Fear & The Silence of the Lambs & A woman follows a dangerous killer into a basement. \\
\hline Anger & My Bodyguard & $\begin{array}{l}\text { A young man is attacked and beaten up by a group of } \\
\text { older pupils. }\end{array}$ \\
\hline Control/Neutral & All the President's Men & Two men are talking to each other in a courtroom. \\
\hline
\end{tabular}

emotion items appeared on the same screen, but their order was randomized across subjects. The participants were asked to rate the extent to which they presently felt each emotion item on a 5-point scale. The response scale ranged from 1 (very slightly or not at all) to 5 (extremely).

As a further check on the strength of the induction, we included a question at the end of the experiment explicitly asking participants whether the film clip made them feel happier, sadder, angrier or more fearful, or whether they did not feel any of these emotions. Our data analysis will focus on those participants for whom the emotion induction did work satisfactorily, that is, who reported having experienced the emotion that the film was supposed to arouse.

\section{Experimental procedures}

The full sequence of events, in all sessions and all treatments, unfolded as follows.

On entering the laboratory, participants were randomly assigned to visually isolated computer terminals. Then all participants received written instructions informing them that the experiment included two parts. To mitigate potential demand effects, participants were immediately given only the instructions for Part 1 . The instructions for Part 2 were distributed after all participants completed Part 1, and did not mention that the PANAS-X questionnaire had to be answered once again. ${ }^{12}$

At the beginning of Part 1, we measured participants' baseline affect. Participants were instructed to read the list of 60 adjective descriptors of emotions from the PANAS$\mathrm{X}$, and to indicate the extent to which the adjectives described their current affective state on a 5-point scale. After completing the PANAS-X questionnaire, participants were asked to express their preferences for each of 100 pairwise lotteries (Hey 2001), as explained above.

Next, the instructions for Part 2 were distributed. The participants were informed that, before starting the second part, they had to watch a film clip. Each participant was asked to put on a headset and to press a 'start' button on the computer. By doing so, they would launch one of five film clips, depending on the experimental treatment. Prior to watching the film clips, the participants were urged to: (i) clear their mind of all thoughts, feelings, and memories; (ii) become involved in the feelings suggested by the situations in the film clip; and (iii) keep these feelings in mind for the remainder of the experiment. These instructions were provided to make the emotion induction effects more intense, 
without exposing the design to the risk of undetectable experimenter demand effects thanks to the presence of the neutral treatment (Westermann et al. 1996).

Immediately after viewing the clips, participants were presented with the same 100 lottery pairs as in Part 1, and asked to indicate their preferred lottery in each pair. The presentation of the lotteries, as well as their left-right positioning, was randomized across parts. After completing this task, participants completed once again the PANAS-X questionnaire, which included the same list of 60 emotions as in Part 1 but in a randomized order to avoid monotonous responses. The emotion manipulation check was included in Part 2 after the main experimental task because we wanted to measure risk attitudes immediately after the target emotion had been manipulated.

Finally, participants were administered a post-experimental questionnaire asking them about (i) demographic characteristics (age, gender and field of study), (ii) participation in previous experiments, (iii) whether or not they had already watched the clip, and (iv) the way the watched clip made them feel.

The design choice of measuring emotions after eliciting risk preferences in Part 2 comes with a cost: as emotions are generally considered to be short-lived affective states, ${ }^{13}$ there is a possibility that their effect fades away before the end of the risk preference elicitation task, and thus before Part 2's emotion manipulation check. To account for this possibility, we include in our analysis only the participants who reported to have felt the intended emotion. We can therefore be certain that the manipulated emotions lasted long enough to eventually affect risk attitudes. It may be argued that the risk elicitation task (rather than the film exposure) could induce the emotions measured in Part 2. Yet this is highly unlikely because the risk elicitation task was identical across all five treatments. Thus if it were responsible for emotion generation, then we should not observe participants reporting the emotion that the film clip is supposed to evoke, which instead we observe. ${ }^{14}$

In order to prompt participants to truthfully report their preferred lottery, we used the random lottery incentive mechanism. ${ }^{15}$ The subjects were informed that at the end of the session, a randomly selected participant would draw a ball from an urn containing two balls, labelled 1 and 2, and that the number on the drawn ball would determine the payoff-relevant part. Then, to pick a problem from the selected part, the same participant had to draw a ticket from an opaque bag containing 100 tickets, numbered 1-100. Each participant was reminded of the choice that she made in the selected problem, played out the preferred lottery for real (using an eight-sided die), and was paid accordingly.

It has been argued that the random lottery incentive mechanism might not elicit true preferences if the subjects are not expected utility maximizers in the sense that they violate the independence axiom (e.g. Holt 1986). However, previous experimental studies indicate that subjects separate each decision task and do not consider the experiment as a single decision problem (Starmer and Sugden 1991; Cubitt et al. 1998; Hey and Lee 2005). If this holds, then the random lottery incentive mechanism elicits true preferences even when testing non-expected utility theories, as we do here. ${ }^{16} \mathrm{~A}$ further caveat is that the random lottery design may cause incentives to be diluted by the fact that each problem has a small probability of being selected and played out for real (Harrison 1994). Hence expected earnings may become negligible. As emphasized above, we selected the possible lottery outcomes to provide appropriate incentives and to minimize this problem: expected earnings from the risk elicitation task were indeed $€ 11.50$, and subjects took approximately 40 minutes to answer the 200 questions. These expected earnings are more than a local student assistant's hourly compensation (namely, €8). It remains true that the cost of 'misbehaviour' (i.e. the foregone expected income of a false 
report) is small and equal to $€ 0.01$ if we multiply the cost of a false report (i.e. the difference in expected values between the left and right lotteries) at any choice question by the probability of that question being selected for payment, which is 1 in 200 . Yet if subjects separate out the individual questions and consider each question in isolation from all the others (as Hey and Lee 2005, among others, show), then the cost of misbehaviour is $€ 2.43$, which is far from being negligible. Moreover, Wilcox (1993) and Beattie and Loomes (1997) provide experimental evidence that subjects' unwillingness to apply the cognitive effort required to identify their truly preferred option is a minor worry in the case of simple pairwise choice problems like those that we use here. ${ }^{17}$

Overall, we ran twelve sessions with a total of 300 participants. Each session lasted less than 2 hours, including distribution and reading of the instructions as well as payment of money. The average payoff was about $€ 20.00$ (inclusive of a show-up fee of $€ 7.50$ ), ranging from a minimum of $€ 7.50$ to a maximum of $€ 31.50$.

\section{THE ECONOMETRIC MODEL}

In round $t$, let us consider a choice problem involving two lotteries, $X_{t}$ and $Y_{t}$. Each lottery comprises, at most, three out of four outcomes. Let us denote the four outcomes of lottery $X_{t}$, for all $t$, in ascending order, as $x_{1}, x_{2}, x_{3}, x_{4}$, occurring with probabilities $p_{1 t}$, $p_{2 t}, p_{3 t}, p_{4 t}$, respectively, with $p_{1 t}+p_{2 t}+p_{3 t}+p_{4 t}=1$. Similarly, let us denote the four outcomes of lottery $Y_{t}$, for all $t$, as $y_{1}, y_{2}, y_{3}, y_{4}$, occurring with probabilities $q_{1 t}, q_{2 t}, q_{3 t}$, $q_{4 t}$, respectively, with $q_{1 t}+q_{2 t}+q_{3 t}+q_{4 t}=1 .{ }^{18}$

Let $u_{i}(z)$ be a utility function, with $z$ being the lottery outcome. We normalize so that $u_{i}(0)=0$ and $u_{i}(\max (z))=1$, where $\max (z)$ is the largest possible outcome, that is, $x_{4}$ or $y_{4}$, which equals $€ 24$. In the absence of error, subject $i$ evaluates the two lotteries $X_{t}$ and $Y_{t}$ as

$$
\begin{aligned}
& V_{i}\left(x_{1}, p_{1 t} ; x_{2}, p_{2 t} ; x_{3}, p_{3 t} ; x_{4}, p_{4 t}\right)=P_{i 2 t} u_{i}\left(x_{2}\right)+P_{i 3 t} u_{i}\left(x_{3}\right)+P_{i 4 t}, \\
& V_{i}\left(y_{1}, q_{1 t} ; y_{2}, q_{2 t} ; y_{3}, q_{3 t} ; y_{4}, q_{4 t}\right)=Q_{i 2 t} u_{i}\left(y_{2}\right)+Q_{i 3 t} u_{i}\left(y_{3}\right)+Q_{i 4 t},
\end{aligned}
$$

where the $P_{i}$ and $Q_{i}$ are transformations of the true probabilities.

As a utility function we adopt the constant relative risk aversion (CRRA) functional form $u_{i}(z)=(z / \max (z))^{\alpha_{i}}$. The parameter $\alpha_{i}>0$ is less than 1 for risk-averse agents, equal to 1 for risk-neutral agents, and greater than 1 for risk-loving agents.

The $P_{i}$ and $Q_{i}$ correspond to the true probabilities in the following way:

$$
\begin{aligned}
& R_{i 2 t}=w_{i}\left(r_{2 t}+r_{3 t}+r_{4 t}\right)-w_{i}\left(r_{3 t}+r_{4 t}\right), \\
& R_{i 3 t}=w_{i}\left(r_{3 t}+r_{4 t}\right)-w_{i}\left(r_{4 t}\right), \\
& R_{i 4 t}=w_{i}\left(r_{4 t}\right)
\end{aligned}
$$

where $w_{i}(r)$ is a probability weighting function of the true probability $r$.

We test different alternative functional forms for $w_{i}(r)$, which can be either linear or non-linear. If the weighting function is linear, that is, $w_{i}(r)=r$, then subjects follow the expected utility theory (EU). If it is non-linear, then subjects follow the rank dependent expected utility theory (RDEU).

As alternative specifications of the weighting function $w_{i}(r)$, we use: 
- Kahneman and Tversky: $w_{i}(r)=\frac{r^{\gamma_{i}}}{\left(r^{\gamma_{i}}+(1-r)^{\gamma_{i}}\right)^{1 / \gamma_{i}}}$;

- Power: $w_{i}(r)=r^{\gamma_{i}}$;

- Prelec: $w_{i}(r)=\exp \left[-(-\ln (r))^{\gamma_{i}}\right]$.

In each specification, the parameter $\gamma_{i}>0$ determines the shape of the weighting function. In all cases, when $\gamma_{i}=1$, there is no probability distortion, and the model reduces to the EU model.

The first weighting function goes back to Kahneman and Tversky (1979). When $0<\gamma_{i}<1$, the probability weighting function assumes an inverse-S shape. When $\gamma_{i}>1$, it takes on an S-shape.

The second specification consists of a concave function when $0<\gamma_{i}<1$, while it assumes a convex form when $\gamma_{i}>1$.

The third functional form was introduced by Prelec (1998). As $\gamma_{i} \rightarrow 0, w_{i}(r)$ becomes a step function that is flat everywhere except at the edges of the probability interval. Similarly to the Kahneman and Tversky specification, the probability weighting function is inverse-S shaped when $0<\gamma_{i}<1$, and S-shaped when $\gamma_{i}>1$.

In detail, the distributional assumptions of the parameters characterizing the EU model are

$$
\ln \left(\alpha_{i}\right) \sim N\left(\mu_{\alpha}, \sigma_{\alpha}^{2}\right), \quad \gamma_{i}=1
$$

The log-normal density function evaluated at $\alpha$ will be denoted as $f\left(\alpha ; \mu_{\alpha}, \sigma_{\alpha}\right)$.

In the RDEU case, the distributional assumptions about the parameters of the model are

$$
\left(\begin{array}{l}
\ln \left(\alpha_{i}\right) \\
\ln \left(\gamma_{i}\right)
\end{array}\right) \sim N\left[\left(\begin{array}{c}
\mu_{\alpha} \\
\mu_{\gamma}
\end{array}\right),\left(\begin{array}{cc}
\sigma_{\alpha}^{2} & \rho \sigma_{\alpha} \sigma_{\gamma} \\
\rho \sigma_{\alpha} \sigma_{\gamma} & \sigma_{\gamma}^{2}
\end{array}\right)\right] .
$$

The bivariate log-normal density function evaluated at $(\alpha, \gamma)$ will be denoted as $g\left(\alpha, \gamma ; \mu_{\alpha}\right.$, $\left.\sigma_{\alpha}, \mu_{\gamma}, \sigma_{\gamma}, \rho\right)$. The parameter $\alpha_{i}$ in the EU model and the parameters $\alpha_{i}$ and $\gamma_{i}$ in the RDEU model represent the unobserved heterogeneity, that is, the individual-specific effects. ${ }^{19}$ Subjects are generally noisy when they choose. To capture this, we assume that they evaluate the difference in the lotteries in each pairwise choice problem with error $\varepsilon_{t}$, known as 'Fechner error', that we assume to be distributed as $N\left(0, \sigma_{\varepsilon}^{2}\right)$, so that the subject chooses $X_{t}\left(Y_{t}\right)$ if and only if ${ }^{20}$

$$
V_{x t}-V_{y t}+\varepsilon_{t}>(<) 0,
$$

where $V_{x t}$ and $V_{y t}$ represent equations (1) and (2), respectively.

Let us use the binary variable $d_{t}=1(-1)$ to indicate that the subject chooses $X_{t}\left(Y_{t}\right)$ in choice problem $t$. Then the likelihood contribution of a single subject's choice in problem $t$, according to the EU theory, is

$$
P\left(d_{t} \mid \alpha, \gamma=1, \sigma_{\varepsilon}\right)=\Phi\left[d_{t}\left(V_{x t}-V_{y t}\right) / \sigma_{\varepsilon}\right], \quad d_{t} \in\{1,-1\}
$$

where $\Phi[\cdot]$ is the standard normal cumulative distribution function. Similarly, the likelihood contribution of a single subject's choice in problem $t$, according to the RDEU 
theory, is

$$
P\left(d_{t} \mid \alpha, \gamma, \sigma_{\varepsilon}\right)=\Phi\left[d_{t}\left(V_{x t}-V_{y t}\right) / \sigma_{\varepsilon}\right], \quad d_{t} \in\{1,-1\}
$$

Considering the 100 choice problems that each subject faces in both parts of the experiment altogether, and integrating out the unobserved heterogeneity, we get the individual likelihood contribution under the EU theory:

$$
L\left(\mu_{\alpha}, \sigma_{\alpha}, \sigma_{\varepsilon}\right)=\int_{0}^{\infty}\left[\prod_{t=1}^{100} P\left(d_{t} \mid \alpha, \gamma=1, \sigma_{\varepsilon}\right)\right] f\left(\alpha ; \mu_{\alpha}, \sigma_{\alpha}\right) \mathrm{d} \alpha
$$

The individual likelihood contribution under the RDEU theory is, instead,

$$
L\left(\mu_{\alpha}, \sigma_{\alpha}, \mu_{\gamma}, \sigma_{\gamma}, \rho, \sigma_{\varepsilon}\right)=\int_{0}^{\infty} \int_{0}^{\infty}\left[\prod_{t=1}^{100} P\left(d_{t} \mid \alpha, \gamma, \sigma_{\varepsilon}\right)\right] g\left(\alpha, \gamma ; \mu_{\alpha}, \sigma_{\alpha}, \mu_{\gamma}, \sigma_{\gamma}, \rho\right) \mathrm{d} \alpha \mathrm{d} \gamma
$$

In order to capture the effect of emotions on the mean of the population, in Part 2, we allow $\mu_{\alpha}$ in the EU case and both $\mu_{\alpha}$ and $\mu_{\gamma}$ in the RDEU case to depend linearly on treatment dummies.

The sample log-likelihood for all subjects is the sum of the logarithms of $L$ given by equations (3) and (4) over all subjects. The models are estimated by maximum simulated likelihood. In order to integrate out the parameters $\alpha$ in equation (3) and $\alpha$ and $\gamma$ in equation (4), we use sequences of 100 (shuffled) Halton draws. ${ }^{21}$

\section{RESULTS}

The analysis that follows is performed on the data collected from 171 participants, that is, all those who declared to have felt the appropriate target emotion. ${ }^{22}$ Before presenting the main results of the study, we check the validity of the random assignment assumption and verify that our experimental manipulation successfully induced the desired emotional states, according to the PANAS-X data.

\section{Demographic characteristics}

We begin our analysis by verifying that the random assignment of students to treatments was effective. This check is important because it has been shown that risk attitudes depend on some personal characteristics such as gender and age (see, for example, Dohmen et al. 2011 and references therein).

Table 2 presents the demographics of our sample and the participations in previous experiments for each treatment. About three-fifths of the participants are female, ranging from $60 \%$ in the joviality treatment to $77 \%$ in the sadness treatment. The average age is around 22, which is not surprising given that subjects are recruited from the undergraduate student population. Approximately one-third of our subjects are enrolled in social science courses, and only a few of them study either business administration or economics. Finally, the rate of participation in previous experiments is rather homogeneous across treatments. According to a series of Kruskal-Wallis (KW) rank- 
TABLE 2

SUMMARY STATISTICS BY TREATMENT

\begin{tabular}{lccccc}
\hline & \multicolumn{5}{c}{ Treatment } \\
\cline { 2 - 6 } & Joviality & Sadness & Fear & Anger & Neutral \\
\hline Subjects & 48 & 31 & 25 & 18 & 49 \\
Female & 0.60 & 0.77 & 0.64 & 0.67 & 0.61 \\
Age & 22.00 & 21.84 & 22.20 & 22.22 & 23.18 \\
Major of study: & & & & & \\
$\quad$ Business administration & 0.10 & 0.10 & 0.12 & 0.05 & 0.11 \\
Economics & 0.00 & 0.00 & 0.08 & 0.05 & 0.00 \\
Engineering & 0.08 & 0.00 & 0.00 & 0.06 & 0.06 \\
Law & 0.02 & 0.07 & 0.04 & 0.05 & 0.10 \\
$\quad$ Medicine & 0.04 & 0.03 & 0.04 & 0.06 & 0.06 \\
Sciences & 0.10 & 0.16 & 0.28 & 0.11 & 0.19 \\
$\quad$ Social sciences & 0.44 & 0.42 & 0.20 & 0.39 & 0.27 \\
$\quad$ Arts and Humanities & 0.13 & 0.16 & 0.24 & 0.06 & 0.12 \\
$\quad$ Other fields & 0.08 & 0.06 & 0.00 & 0.17 & 0.10 \\
Number of experiments: & & & & & \\
$\quad$ None & 0.06 & 0.00 & 0.00 & 0.05 & 0.02 \\
$\quad$ Less than 4 & 0.21 & 0.19 & 0.40 & 0.11 & 0.16 \\
$\quad$ Between 4 and 8 & 0.48 & 0.55 & 0.44 & 0.56 & 0.59 \\
$\quad$ More than 8 & 0.25 & 0.26 & 0.16 & 0.28 & 0.23 \\
\hline
\end{tabular}

Notes

Relative frequencies for gender, major of study and number of experiments; means for age.

sum tests, there are no significant differences in any of the individual characteristics across treatments ( $p$-values equal to $0.581,0.579,0.774$, and 0.461 for gender, age, major of study and number of previous experiments, respectively). The random assignment assumption cannot therefore be rejected. ${ }^{23}$

\section{Emotions manipulation check}

To avoid revealing our interest in specific emotions, we included all 60 affective items listed in the PANAS-X questionnaire, although only 25 are of interest. The joviality factor includes 'cheerful', 'delighted', 'happy', 'joyful', 'excited', 'lively', 'enthusiastic' and 'energetic' (Cronbach's $\alpha \geq 0.90$ in both parts of the experiment). The sadness factor includes 'sad', 'blue', 'alone', 'lonely' and 'downhearted' ( $\alpha \geq 0.77$ in both parts). The fear factor includes 'afraid', 'shaky', 'nervous', 'jittery', 'scared' and 'frightened' $\alpha \geq 0.78$ in both parts). Finally, the anger factor includes 'disgusted', 'scornful', 'irritable', 'angry', 'hostile' and 'loathing' ( $\alpha \geq 0.76$ in both parts). All factors display a good level of internal consistency reliability. ${ }^{24}$

To analyse emotions data and to exploit the within-subject design, we proceed as follows. First, we create 25 indicator variables, one for each of the 25 aforementioned items. Each indicator takes value 1 if the participant rates the corresponding item higher in the second part of the experiment (after the emotion manipulation) than in the first part, 0 otherwise. Once we have coded (as 0 or 1 ) each individual item, we proceed to the second step. For each subject, we aggregate the indicator variables into four emotional classes, each containing the items specified above. We aggregate by summing the 
indicator variables that refer to the items in the same emotion. Taking, for example, 'joviality', which is made up of 8 items, each subject's aggregate indicator variable for joviality can range from 0 (if the subject rates no item higher in Part 2) to 8 (if the subject assigns a higher score to all 8 items in Part 2). For each emotion, we can thus construct a vector with length equal to the number of subjects in each treatment, whose components indicate how many items a subject rates higher in Part $2 .{ }^{25}$ The vectors so obtained identify the joviality, sadness, fear and anger factors that we compare across treatments and within each treatment. The across-treatment comparisons enable us to check whether a specific emotion is more present in the corresponding treatment than in the other treatments. The within-treatment comparisons reveal whether the right emotion has been induced in a specific treatment.

Summary statistics of the emotional factors are reported in Table 3, separately for each treatment. On average, participants in the joviality treatment assign a higher score to 2.02 items of the joviality factor in Part 2. Participants in the other treatments increase the rating of fewer items of the joviality factor; the difference across treatments is statistically significant according to a Kruskal-Wallis $(\mathrm{KW})$ rank-sum test ( $p$-value 0.0004). Moreover, in the joviality treatment, following the emotion induction, more items are rated higher for the joviality factor than for any other emotional factor (onesided Wilcoxon signed-rank tests comparing the joviality factor with each one of the other emotional factors, all $p$-values $\leq 0.001$ ). We take this as an indication that When Harry met Sally successfully induced joviality.

Turning to our manipulation of negative emotions, The Champ leads participants in the sadness treatment to increase the score of 1.94 items of the sadness factor, on average. This is significantly more than the number of items of the sadness factor that are rated higher in all the other treatments (KW 29.35, p-value 0.0001). After watching the film clip, more items of the fear factor ( 2 on average) are rated higher in the fear treatment than in any other treatment (KW 23.79, p-value 0.0001). In Part 2 of the anger treatment, we obtain a similar result. In particular, a larger number of items of the anger factor (2 on average) are rated higher in the anger treatment than in any other treatment ( $\mathrm{KW}$ 19.37, $p$-value 0.001). ${ }^{26}$ Within-treatment comparisons show that participants in the sadness, fear and anger treatments increase the score of more items of the manipulated emotion than of any other emotion. According to a series of Wilcoxon signed-rank tests, in each treatment there are significantly more increased items for the manipulated emotion than for the other emotions; the difference is significant at the $5 \%$ level in almost all comparisons, except for (i) the comparisons between the sadness factor and the fear factor in the sadness treatment, and between the anger factor and the sadness factor in

TABLE 3

EMOTIONAL FACTORS BY TREATMENT

\begin{tabular}{lccccr}
\hline & \multicolumn{5}{c}{ Treatment } \\
\cline { 2 - 6 } Factor & Joviality & Sadness & Fear & Anger & Neutral \\
\hline Joviality & $2.02(1.76)$ & $1.03(1.22)$ & $1.08(1.50)$ & $0.61(0.61)$ & $1.92(1.55)$ \\
Sadness & $0.44(0.94)$ & $1.94(1.61)$ & $1.00(1.04)$ & $1.22(1.44)$ & $0.57(0.84)$ \\
Fear & $1.06(1.26)$ & $1.48(1.29)$ & $2.00(1.47)$ & $1.56(1.42)$ & $0.63(0.88)$ \\
Anger & $0.54(1.13)$ & $0.74(1.00)$ & $0.96(1.10)$ & $2.00(2.09)$ & $0.29(0.54)$ \\
\hline
\end{tabular}

Notes

Average number of items that are rated higher after the emotion manipulation by emotional factor and treatment. Standard deviations are reported in parentheses. 
the anger treatment, which are significant at the $10 \%$ level, and (ii) the comparison between the anger factor and the fear factor in the anger treatment, which is not significant. Based on these findings and on the restriction of our sample to those who declared to have felt the appropriate emotion, we are confident about the efficacy of our negative emotion induction.

\section{Risk preferences}

Table 4 presents the maximum likelihood estimates of the four preference functionals described in Section II. The models, which are estimated with a Fechner error term, ${ }^{27}$ are displayed in the following order: EU, RDEU with the Kahneman and Tversky (KT) specification of the weighting function, RDEU with the Power specification, RDEU with the Prelec specification. For each model, there are two columns of estimated coefficients, labelled 'Part 1' and 'Part 2'. Part 1 (Part 2) indicates that the model has been fitted on the 100 choices faced before (after) stimulating subjects' emotions. Part 1 data are estimated without distinguishing between emotions because emotions are manipulated at the end of the first part. Part 2 data are estimated, instead, allowing the means of the relevant coefficients ( $\mu_{\alpha}$ in the EU case, and both $\mu_{\alpha}$ and $\mu_{\gamma}$ in the RDEU cases) to vary with the treatment. In Part 2, the constant represents the mean estimated from the control treatment (with no emotion elicitation), while the estimated coefficients on the treatment dummies are deviations from the control attributable to the effect of emotions.

According to the likelihood ratio test, each of the estimated RDEU models fits better than the EU model, for both Part 1 and Part 2 data. We can thus focus only on the alternative specifications of the RDEU model. Since all the considered specifications have the same number of parameters, any criterion of the AIC or BIC type would apply the same penalization factor to all of them. What matters, when all is said and done, is the log-likelihood of the fits. According to such a measure, the RDEU specification that fits the data best is RDEU/Power for both Part 1 and Part 2. Consequently, we will concentrate the following discussion on this specification, which applies a monotonically increasing or decreasing weight on probabilities.

For the chosen specification, three remarks are in order. First, the variability is considerable for both $\mu_{\alpha}$ and $\mu_{\gamma}$ : although $\sigma_{\gamma}$ significantly reduces in Part 2 compared to Part 1, it still accounts for a large amount of heterogeneity across subjects. Second, the correlation coefficient $\rho$ is estimated to be positive, statistically significant, and quite significant (it is around 0.30 in both Part 1 and Part 2). The implication of this finding is rather interesting. This is telling us that those who have a small $\alpha$ tend also to have a small $\gamma$, and vice versa. In other words, the more risk-averse people are, the more they tend to overweight large outcomes. Third, the standard deviation of the Fechner error term, $\sigma_{\varepsilon}$, is rather small in both parts $(\leq 0.057)$. These error values are consistent with those observed in previous empirical studies. ${ }^{28}$

Although the estimated parameters of the underlying bivariate normal distribution of $\alpha$ and $\gamma$, reported in Table 4, provide information about whether there is a change in the coefficients of the treatment dummies compared to the control, to determine whether emotions affect risk attitudes, we consider the means of $\alpha$ and $\gamma$, which follow a bivariate log-normal distribution and are derived from Table 4's estimated parameters in the following way: the mean of $\alpha$ equals $\exp \left(\mu_{\alpha}+\sigma_{\alpha}^{2} / 2\right)$, and the mean of $\gamma$ equals $\exp \left(\mu_{\gamma}+\sigma_{\gamma}^{2} / 2\right)$. These means have the great advantage of allowing an immediate interpretation. As a matter of fact, when the mean of the risk attitude coefficient $\alpha$ is lower (greater) than 1, people are risk-averse (risk-seeking); when $\alpha$ is equal to 1 , they are risk- 


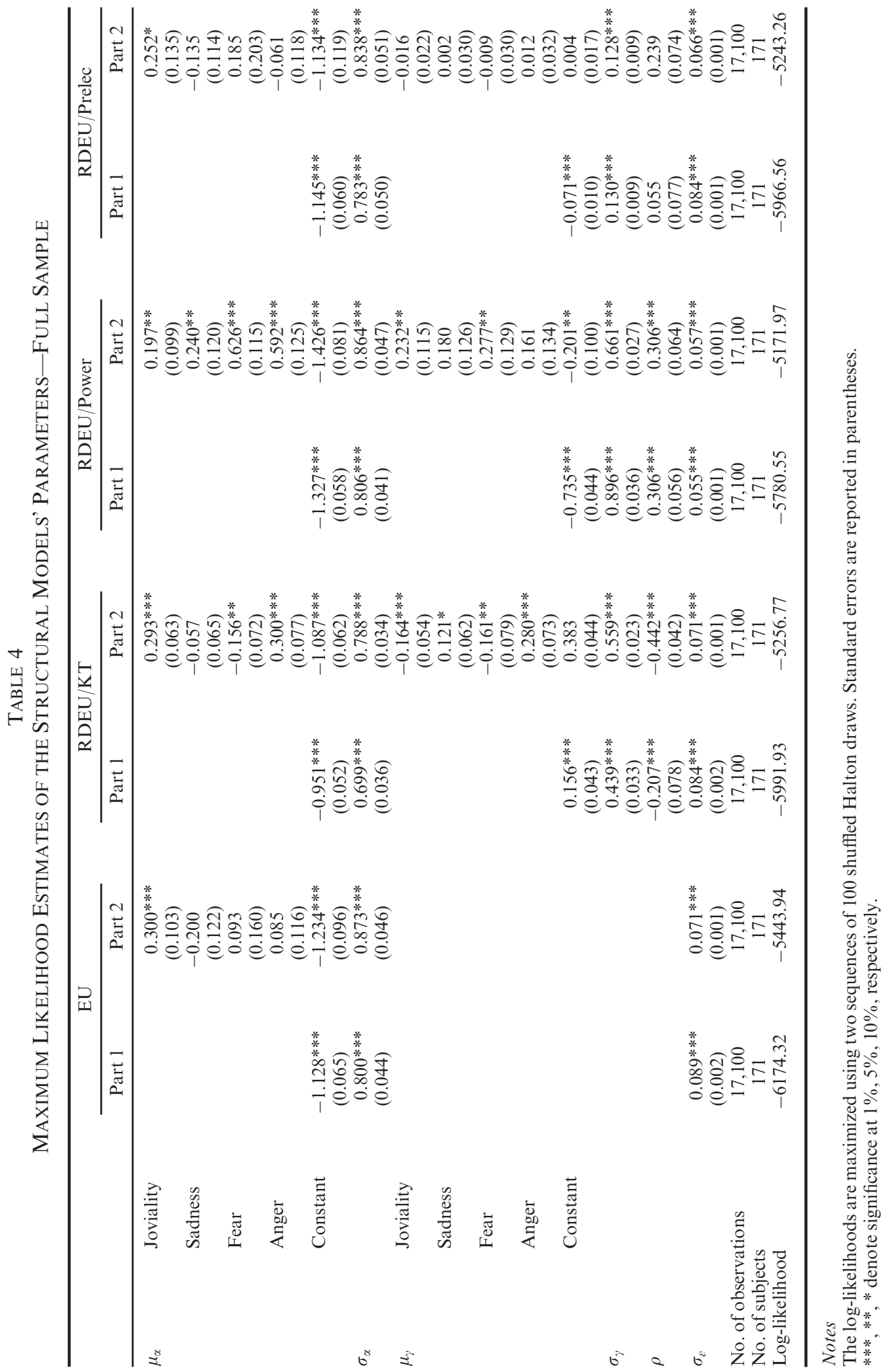


neutral. As to the mean of the (Power) weighting function parameter, when $\gamma<1$, people tend to overvalue (undervalue) the probability of the largest (smallest) outcome(s), whereas when $\gamma>1$, people tend to underweight (overweight) the largest (smallest) outcome(s).

The 'Parameters' columns in Table 5 show the means of the log-normal distribution of $\alpha$ and $\gamma$ for both Part 1 and Part 2. In line with the estimates in Table 4, Part 1 data result in a single parameter, while Part 2 data comprise a parameter value for each of the five treatments. The last column of Table 5 presents the $p$-values of Wald tests of equality of the estimated parameters between (i) Part 1 and the neutral treatment, (ii) each treatment dummy and the neutral treatment, and (iii) the different emotion treatments. Comparison (i) allows us to verify whether there is a change in the means of $\alpha$ and $\gamma$ between Part 1 and Part 2 due to, for example, experimenter demand effects or whatever other reason not directly attributable to the emotion manipulation, like subjects getting used to the choice task or subjects' inconsistencies. The four pairwise comparisons (ii) serve to demonstrate the effect of emotions on risk attitudes. The pairwise comparisons (iii) enable us to detect any (statistically) significant difference in risk preferences between the induced emotions.

TABLE 5

MEANS OF THE LOG-NORMAL DisTRIBUTION OF THE PARAMETERS OF INTEREST AND RELATED TESTS-Full SAMPLE

\begin{tabular}{|c|c|c|c|c|}
\hline & \multicolumn{2}{|c|}{ Parameters } & \multirow[b]{2}{*}{ Wald tests } & \multirow[b]{2}{*}{$p$-value } \\
\hline & Part 1 & Part 2 & & \\
\hline$\alpha$ & $\begin{array}{c}0.367 \\
(0.020)\end{array}$ & & Part 1 vs. Neutral & 0.515 \\
\hline Neutral & & $\begin{array}{c}0.349 \\
(0.027)\end{array}$ & $\begin{array}{l}\text { Joviality vs. Neutral } \\
\text { Sadness vs. Neutral }\end{array}$ & $\begin{array}{l}0.045 \\
0.049\end{array}$ \\
\hline Joviality & & $\begin{array}{c}0.425 \\
(0.028)\end{array}$ & $\begin{array}{l}\text { Fear vs. Neutral } \\
\text { Anger vs. Neutral }\end{array}$ & $\begin{array}{l}0.000 \\
0.000\end{array}$ \\
\hline Sadness & & $\begin{array}{c}0.444 \\
(0.036)\end{array}$ & $\begin{array}{c}\text { Joviality vs. Sadness } \\
\text { Joviality vs. Fear }\end{array}$ & $\begin{array}{l}0.718 \\
0.000\end{array}$ \\
\hline Fear & & $\begin{array}{c}0.653 \\
(0.058)\end{array}$ & $\begin{array}{l}\text { Joviality vs. Anger } \\
\text { Sadness vs. Fear }\end{array}$ & $\begin{array}{l}0.003 \\
0.004\end{array}$ \\
\hline Anger & & $\begin{array}{c}0.631 \\
(0.064)\end{array}$ & $\begin{array}{l}\text { Sadness vs. Anger } \\
\text { Fear vs. Anger }\end{array}$ & $\begin{array}{l}0.011 \\
0.794\end{array}$ \\
\hline$\gamma$ & $\begin{array}{c}0.717 \\
(0.027)\end{array}$ & & Part 1 vs. Neutral & 0.004 \\
\hline Neutral & & $\begin{array}{c}1.018 \\
(0.105)\end{array}$ & $\begin{array}{l}\text { Joviality vs. Neutral } \\
\text { Sadness vs. Neutral }\end{array}$ & $\begin{array}{l}0.035 \\
0.145\end{array}$ \\
\hline Joviality & & $\begin{array}{c}1.282 \\
(0.087)\end{array}$ & $\begin{array}{l}\text { Fear vs. Neutral } \\
\text { Anger vs. Neutral }\end{array}$ & $\begin{array}{l}0.031 \\
0.232\end{array}$ \\
\hline Sadness & & $\begin{array}{c}1.218 \\
(0.100)\end{array}$ & $\begin{array}{c}\text { Joviality vs. Sadness } \\
\text { Joviality vs. Fear }\end{array}$ & $\begin{array}{l}0.548 \\
0.657\end{array}$ \\
\hline Fear & & $\begin{array}{l}1.343 \\
(0.119)\end{array}$ & $\begin{array}{l}\text { Joviality vs. Anger } \\
\text { Sadness vs. Fear }\end{array}$ & $\begin{array}{l}0.491 \\
0.388\end{array}$ \\
\hline Anger & & $\begin{array}{c}1.194 \\
(0.110)\end{array}$ & $\begin{array}{l}\text { Sadness vs. Anger } \\
\text { Fear vs. Anger }\end{array}$ & $\begin{array}{l}0.857 \\
0.342\end{array}$ \\
\hline
\end{tabular}

Notes

The number of observations is as in Table 4. The standard errors of the estimated parameters (reported in parentheses) are obtained with the Delta method. All parameters are significant at the $1 \%$ level. 
The mean of the risk attitude parameter $(\alpha)$ does not change significantly between Part 1 and the neutral treatment as it can be deduced by comparing the estimate of the mean of $\alpha$ from Part 1 data with that from the neutral treatment data in Part 2 ( 0.367 vs. $0.349, p$-value 0.515$)$. This means that participants exposed to the neutral affect film do not modify significantly their risk preferences compared to Part 1, thereby ensuring that the within-subject design used in this study did not induce undesirable experimenter demand effects. Conversely, the same comparison performed on the mean of the weighting function parameter $(\gamma)$ indicates that there is a change between Part 1 and the neutral treatment $(0.717$ vs. $1.018, p$-value 0.004$)$, implying that participants tend to become less optimistic in Part 2.

Turning to the main purpose of the paper-that is, if and how emotions change risk preferences - we can see that all the emotions significantly increase the mean of the risk attitude parameter compared to the control (neutral) group ( $p$-value $\leq 0.049$ for all four comparisons). This finding implies that joyful, sad, fearful and angry subjects tend to be significantly less risk-averse than subjects in a neutral affective state. Furthermore, our results show that compared to the neutral treatment, joviality and fear have some influence on $\gamma$ ( $p$-values 0.035 and 0.031 , respectively).

A significant difference is also detected when we compare $\alpha$ between emotion treatments, except for the comparisons between joviality and sadness ( $p$-value 0.718 ) and fear and anger ( $p$-value 0.794$)$. Thus compared to participants in the treatments inducing joy and sadness, fearful and angry participants are significantly more prone to take risk.

It is worth noting that had we used any of the other specifications of the RDEU models that we have considered, we would have reported different estimates and different statistically significant effects of some emotions on the mean of the risk attitude parameter. This highlights the importance of selecting the model that best represents the data and might provide an explanation for the opposite effects that we can find in the literature.

There is evidence that gender plays an important role in decision-making under risk. In particular, women are generally found to be more risk-averse than men (see the review on gender differences by Croson and Gneezy 2009). To verify whether the effects spotted from the entire sample hold for both males and females, or whether emotions affect risk attitudes differently for men and women, we have divided the sample by gender. ${ }^{29}$ The parameters estimated by the econometric models (RDEU/Power specification) are reported in the first four columns of Table 6 , separately for males and females. The corresponding means of the log-normal distribution of $\alpha$ and $\gamma$ for the subsamples of males and females and the related Wald tests are displayed in Table 7.

It turns out that the analysis is meaningful: gender differences show up. Specifically, while sadness strongly increases male risk aversion ( $p$-value 0.013 ), joviality has a significant impact on female risk attitudes only ( $p$-value 0.004). Fear increases both male ( $p$-value 0.025 ) and female ( $p$-value 0.006$)$ risk attitudes. Anger, on the other hand, does not significantly affect either male or female risk attitudes ( $p$-values $\geq 0.277$ ). Moreover, in line with previous studies, females are estimated to be significantly more risk-averse than males in both parts of the experiment ( $p$-value $\leq 0.008$ in both cases). Concerning the weighting function parameter, we notice that whatever the gender, the estimate of the mean of $\gamma$ from the neutral treatment data in Part 2 exceeds that from Part 1 data, meaning that both males and females exhibit an increase in $\gamma$ from Part 1 to Part 2 of the experiment. The increase is, however, significant only for females ( $p$-value 0.000$)$. Fearful males and females experience an even bigger increase in the mean of the weighting function parameter. 


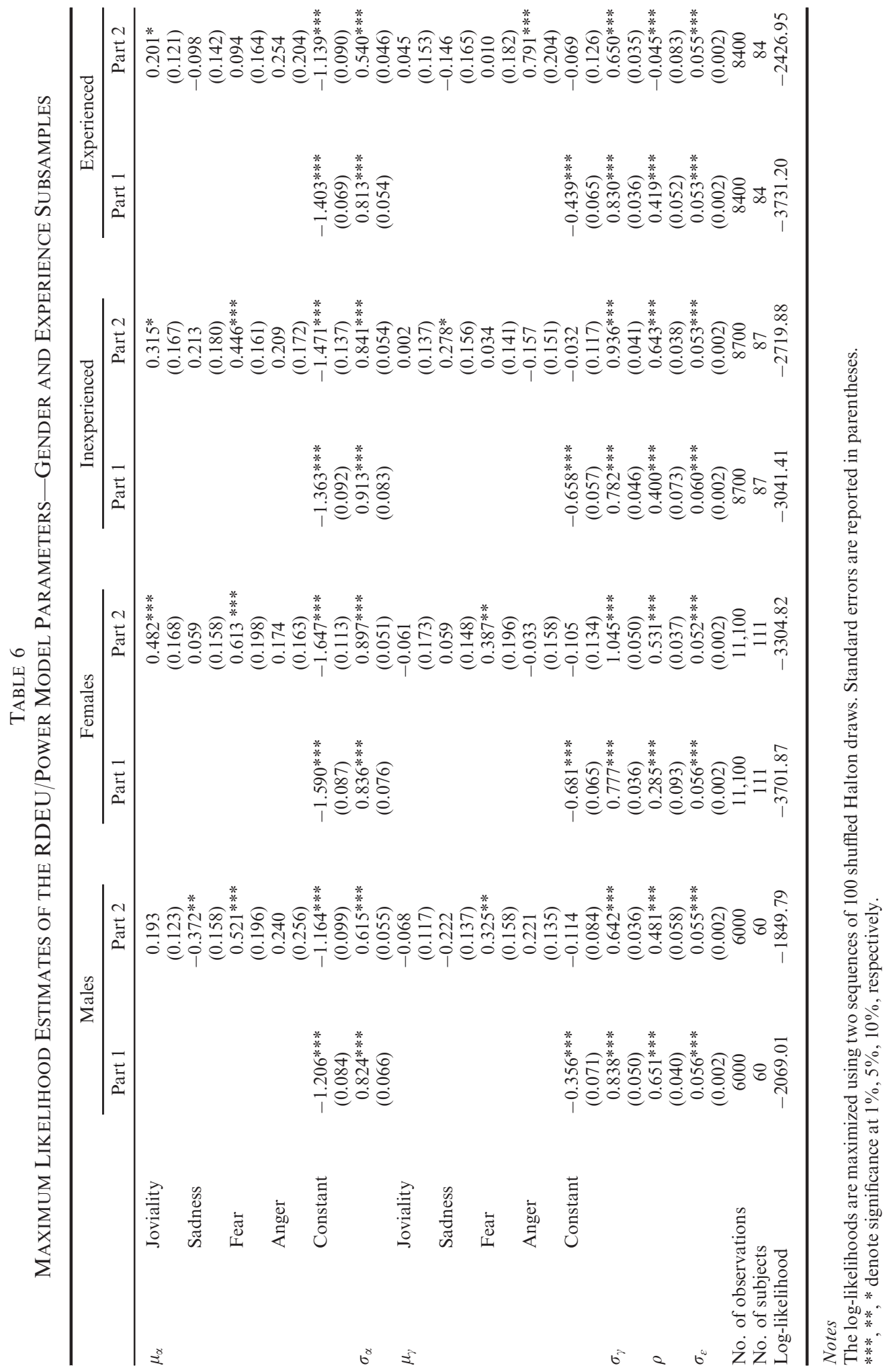


TABLE 7

MEANS OF THE Log-Normal Distribution of THE PARAMETERS OF INTEREST AND RELATED TESTS-GENDER SUBSAMPLE

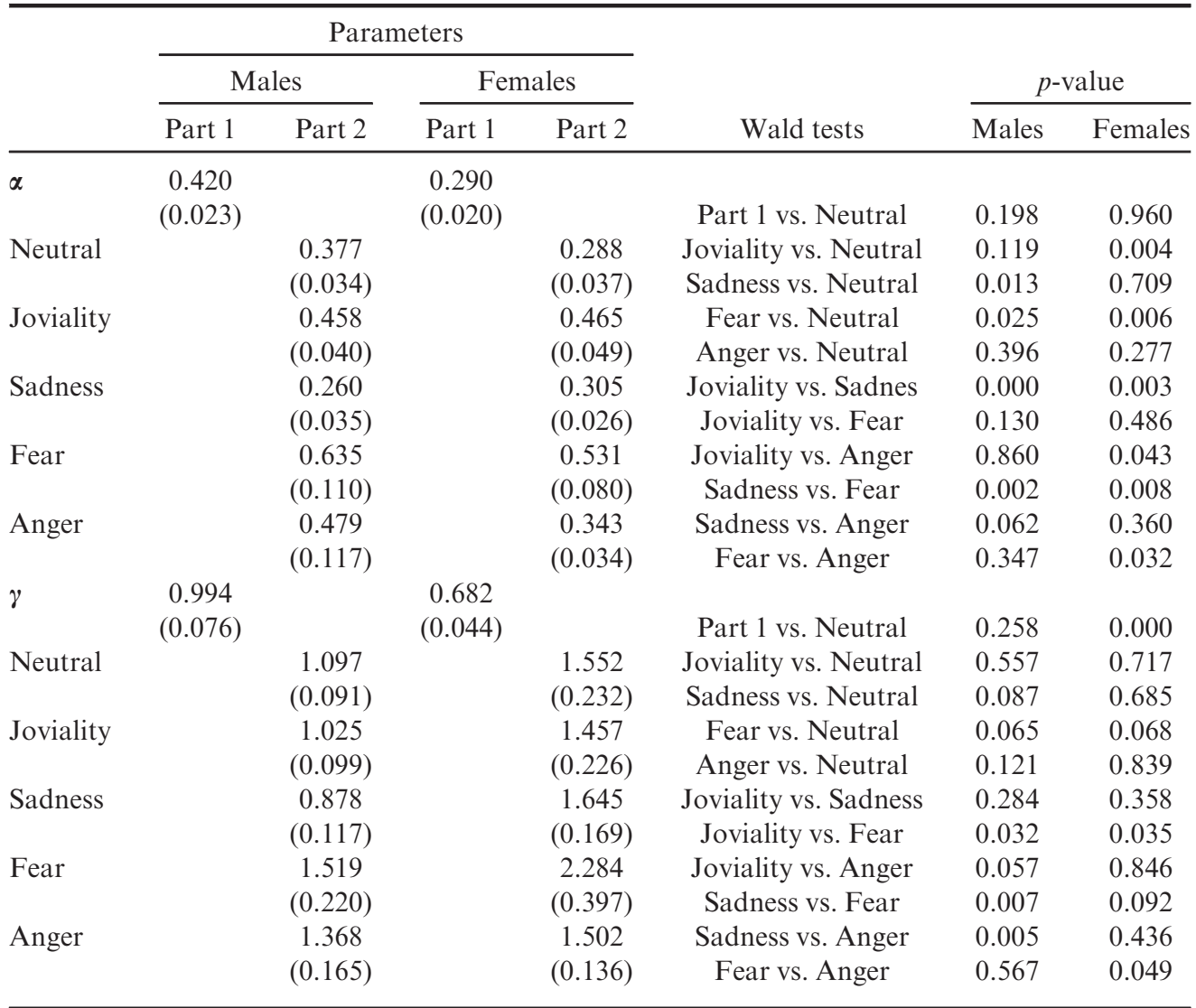

Notes

The number of observations for males and females are as in Table 6. The standard errors of the estimated parameters (reported in parentheses) are obtained with the Delta method. All parameters are significant at the $1 \%$ level.

The last four columns of Table 6 display the estimates of the RDEU/Power model parameters obtained by dividing the sample according to subjects' previous participation in laboratory experiments. We refer to subjects who participated in at most 6 experiments as inexperienced, and to subjects who took part in more than 6 experiments as experienced. ${ }^{30}$ The corresponding means of $\alpha$ and $\gamma$, as well as the related Wald tests, are reported in Table 8.

Somewhat in line with our expectation that emotions would affect less the risk preferences of the experienced, we find that joviality and fear lead only the inexperienced to be significantly less risk-averse (at a significance level of 5\%). As for $\gamma$, whereas the inexperienced's weighting parameter is affected positively and weakly significantly by sadness ( $p$-value 0.079), the weighting parameter of the experienced is strongly significantly influenced by anger ( $p$-value 0.003$)$. 
TABLE 8

MeAns of the Log-Normal Distribution of the PARAMETERS OF INTEREST AND RELATED TESTS-EXPERIENCE SUBSAMPLE

\begin{tabular}{|c|c|c|c|c|c|c|c|}
\hline & \multicolumn{4}{|c|}{ Parameters } & \multirow[b]{3}{*}{ Wald tests } & \multirow{2}{*}{\multicolumn{2}{|c|}{$p$-value }} \\
\hline & \multicolumn{2}{|c|}{ Inexperienced } & \multicolumn{2}{|c|}{ Experienced } & & & \\
\hline & Part 1 & Part 2 & Part 1 & Part 2 & & In. & Ex. \\
\hline$\alpha$ & $\begin{array}{l}0.388 \\
(0.023)\end{array}$ & & $\begin{array}{c}0.343 \\
(0.019)\end{array}$ & & Part 1 vs. Neutral & 0.177 & 0.397 \\
\hline Neutral & & $\begin{array}{c}0.327 \\
(0.045)\end{array}$ & & $\begin{array}{c}0.371 \\
(0.032)\end{array}$ & $\begin{array}{l}\text { Joviality vs. Neutral } \\
\text { Sadness vs. Neutral }\end{array}$ & $\begin{array}{l}0.047 \\
0.227\end{array}$ & $\begin{array}{l}0.099 \\
0.473\end{array}$ \\
\hline Joviality & & $\begin{array}{l}0.448 \\
(0.037)\end{array}$ & & $\begin{array}{l}0.453 \\
(0.039)\end{array}$ & $\begin{array}{l}\text { Fear vs. Neutral } \\
\text { Anger vs. Neutral }\end{array}$ & $\begin{array}{l}0.003 \\
0.215\end{array}$ & $\begin{array}{l}0.570 \\
0.259\end{array}$ \\
\hline Sadness & & $\begin{array}{l}0.405 \\
(0.042)\end{array}$ & & $\begin{array}{c}0.335 \\
(0.040)\end{array}$ & $\begin{array}{c}\text { Joviality vs. Sadness } \\
\text { Joviality vs. Fear }\end{array}$ & $\begin{array}{l}0.368 \\
0.280\end{array}$ & $\begin{array}{l}0.036 \\
0.507\end{array}$ \\
\hline Fear & & $\begin{array}{l}0.511 \\
(0.045)\end{array}$ & & $\begin{array}{c}0.408 \\
(0.058)\end{array}$ & $\begin{array}{l}\text { Joviality vs. Anger } \\
\text { Sadness vs. Fear }\end{array}$ & $\begin{array}{l}0.386 \\
0.086\end{array}$ & $\begin{array}{l}0.801 \\
0.291\end{array}$ \\
\hline Anger & & $\begin{array}{c}0.403 \\
(0.041)\end{array}$ & & $\begin{array}{c}0.477 \\
(0.090)\end{array}$ & $\begin{array}{l}\text { Sadness vs. Anger } \\
\text { Fear vs. Anger }\end{array}$ & $\begin{array}{l}0.975 \\
0.076\end{array}$ & $\begin{array}{l}0.142 \\
0.507\end{array}$ \\
\hline$\gamma$ & $\begin{array}{c}0.702 \\
(0.039)\end{array}$ & & $\begin{array}{c}0.095 \\
(0.065)\end{array}$ & & Part 1 vs. Neutral & 0.000 & 0.106 \\
\hline Neutral & & $\begin{array}{l}1.500 \\
(0.185)\end{array}$ & & $\begin{array}{l}1.552 \\
(0.153)\end{array}$ & $\begin{array}{l}\text { Joviality vs. Neutral } \\
\text { Sadness vs. Neutral }\end{array}$ & $\begin{array}{l}0.991 \\
0.079\end{array}$ & $\begin{array}{l}0.762 \\
0.385\end{array}$ \\
\hline Joviality & & $\begin{array}{l}1.503 \\
(0.129)\end{array}$ & & $\begin{array}{l}1.206 \\
(0.115)\end{array}$ & $\begin{array}{l}\text { Fear vs. Neutral } \\
\text { Anger vs. Neutral }\end{array}$ & $\begin{array}{l}0.808 \\
0.309\end{array}$ & $\begin{array}{l}0.956 \\
0.003\end{array}$ \\
\hline Sadness & & $\begin{array}{l}1.982 \\
(0.236)\end{array}$ & & $\begin{array}{c}0.993 \\
(0.099)\end{array}$ & $\begin{array}{c}\text { Joviality vs. Sadness } \\
\text { Joviality vs. Fear }\end{array}$ & $\begin{array}{l}0.026 \\
0.772\end{array}$ & $\begin{array}{l}0.121 \\
0.807\end{array}$ \\
\hline Fear & & $\begin{array}{l}1.552 \\
(0.146)\end{array}$ & & $\begin{array}{l}1.163 \\
(0.148)\end{array}$ & $\begin{array}{l}\text { Joviality vs. Anger } \\
\text { Sadness vs. Fear }\end{array}$ & $\begin{array}{l}0.160 \\
0.083\end{array}$ & $\begin{array}{l}0.006 \\
0.307\end{array}$ \\
\hline Anger & & $\begin{array}{l}1.283 \\
(0.140)\end{array}$ & & $\begin{array}{c}2.540 \\
(0.462)\end{array}$ & $\begin{array}{l}\text { Sadness vs. Anger } \\
\text { Fear vs. Anger }\end{array}$ & $\begin{array}{l}0.002 \\
0.129\end{array}$ & $\begin{array}{l}0.002 \\
0.006\end{array}$ \\
\hline
\end{tabular}

Notes

The number of observations for inexperienced ('In.') and experienced ('Ex.') are as in Table 6. The standard errors of the estimated parameters (reported in parentheses) are obtained with the Delta method. All parameters are significant at the $1 \%$ level.

\section{CONCLUSIONS}

Our study contributes to the literature on the role of emotions in decision-making under risk. By means of an experiment providing participants with salient monetary incentives and meeting state-of-the-art methodological criteria, we find that a positive emotion (namely joviality) as well as three negative emotions (namely sadness, fear and anger) lessen risk aversion. We obtained this result by estimating an econometric model that controls for heterogeneity both within subjects and between subjects. We select the model that fits the pooled data best from a set of four different specifications of the functional form.

The finding that joyful participants are less risk-averse than participants in a neutral affective state provides partial support for the affect infusion model (Forgas 1995), asserting that individuals who are in a positive emotional state rely on positive cues when making judgments, and thus tend to perceive a risky task as favourable. The affect 
infusion model is not fully supported by our data because it predicts that individuals who are in a negative emotional state should behave in the opposite way and thus be more likely to make conservative risky decisions.

We observe, instead, that sad, fearful and angry participants are more prone to take risk compared to participants in a neutral affective state, therefore acting in line with the mood maintenance hypothesis (Isen and Patrick 1983). The general claim of this hypothesis is that the effect of mood on risk preferences can be explained through a desire to maintain a positive affective state or to mitigate a negative one. Along this line of reasoning, people experiencing negative emotions should be willing to take risk because they hope to improve their state.

We focused on specific negative emotions, rather than on global negative and positive affect, because previous studies (like, for example, Raghunathan and Pham 1999; Lerner and Keltner 2001; Kugler et al. 2012) indicate that affective states of the same valence can induce opposing risk attitudes. Remarkably, our results suggest otherwise: different negative emotions have the same effect on risk-taking behaviour. This finding is, however, consistent with the mood repair hypothesis, according to which people in negative affective states are willing to make risky choices in order to obtain an outcome that would make them feel happy.

Our data therefore show that positive and negative emotions involve separate cognitive processes, so that different models are needed to explain their effect on risk preferences. Joyful participants, who are in a positive emotional state, seem to be likely to appraise the risk positively. Sad, fearful and angry participants, who are in a negative emotional state, rather than behaving in an opposite way and evaluating the risk negatively, appear to be willing to change this undesired state. After all, maintaining negative affective states is probably not a goal for most people. Understanding the reasons for the different cognitive mechanisms induced by negative and positive emotions would enrich the picture painted here, but is beyond the scope of the current study.

We confirm the result (see, for example, Croson and Gneezy 2009) that females are more risk-averse than males; in our sample, this holds true both before and after the emotion manipulation. Moreover, in line with Fehr-Duda et al. (2011), we show the existence of gender differences in the role of emotions in risk-taking behaviour. We find that the male willingness to take risk is positively influenced by sadness, while only joviality affects the female risk attitudes. Finally, our analysis of whether emotions impact risk preferences differently depending on subjects' previous laboratory experience indicates that the only difference between experienced and inexperienced participants is that the latter (but not the former) are affected by fear.

Our results are only partially consistent with previous research on emotions. This inconsistency may be due to the method that we employed to identify and estimate risk attitudes. Future research will have to assess the robustness of our findings using the same econometric technique, but different sample pools and/or different emotions.

\section{ACKNOWLEDGMENTS}

We gratefully acknowledge the financial support of the Max Planck Institute of Economics, Jena (Germany). We are indebted to the editor, Frank Cowell, one anonymous referee, and Ivan Soraperra for useful remarks and suggestions. Also, comments by participants in the Workshop on Behavioural Economics: Science, Philosophy, and Policy-Making (Trento), the 8th Alhambra Experimental Workshop (Rome), and seminars at the Economic and Social Research Institute (Dublin) and the University of Cambridge are gratefully acknowledged. The usual disclaimer applies. 


\section{NOTES}

1. Economists commonly use the terms 'affect', 'mood' and 'emotion' as synonyms. Psychologists, instead, tend to make clear distinctions among them. Robbins and Judge (2012, ch. 4, p. 98) define these terms as follows: 'Affect is a generic term that covers a broad range of feelings people experience, including both emotions and moods. Emotions are intense feelings directed at someone or something. Moods are less intense feelings than emotions and often (though not always) arise without a specific event acting as a stimulus.' We adhere to these meanings of the terms, and thus, since we use visual stimuli-namely film clips - as induction procedure, we refer to emotions rather than moods. In doing so, we follow, for example, Gross and Levenson (1995), Lerner et al. (2004), and Gino and Schweitzer (2008). We acknowledge, however, that there are authors (such as Treffers et al. 2012) who prefer using the term 'mood' with an induction procedure based on film clips. In this work, the terms 'emotion', 'affective state' and 'emotional state' are used interchangeably.

2. Notable exceptions are Lee and Andrade (2011), van Winden et al. (2011) and Treffers et al. (2012).

3. As Friedman and Sunder (1994) point out, preferences toward risk are the most important characteristic that economic theory recognizes to vary across individuals.

4. See, for instance, Treffers et al. (2012) or Drichoutis and Nayga (2013).

5. For advantages and pitfalls of MPLs, see also Charness et al. (2013).

6. The literature has proposed several alternative procedures to elicit emotions (e.g. images, sounds, selfstatements, distribution of cookies or candies, relived or imagined scenes, music, and odours). Film clips have turned out to be one of the most powerful methods (Westermann et al. 1996; Lerner and Keltner 2001).

7. Lerner et al. (2003) study the emotional reaction to the 11 September terrorist attack, surveying members of a nationally representative sample of Americans. They find that, compared to females, males express more anger, less fear, and less pessimistic risk estimates, and that differences in reported emotions explain a large part of the gender difference. Fessler et al. (2004) show that anger leads men (but not women) to make riskier choices, whereas disgust leads women (but not men) to make less risky choices. Finally, Fehr-Duda et al. (2011) find that women in a better than usual mood tend to weight probabilities more optimistically (while men do not).

8. We did not allow the participants to indicate indifference. The reasons for doing so are outlined in Hey (2001, p. 53).

9. Previous research has shown that colours can affect emotions, mood and feelings (e.g. Cimbalo et al. 1978; Bellizzi and Hite 1992). Hence, in order not to confound our emotion manipulation, segmented circles were displayed on the grey scale.

10. We use the German translation of the PANAS-X questionnaire provided by Röcke and Grühn (2003), which is based on Krohne et al. (1996).

11. These emotions are fear, hostility, guilt, sadness, joviality, self-assurance, attentiveness, shyness, fatigue, serenity and surprise.

12. An English translation of the instructions can be found in the Online Appendix.

13. While most of those who distinguish emotions from moods maintain that moods endure longer, there is no agreement about the duration of emotions. Some authors suggest that emotions last a matter of minutes, sometimes even seconds (e.g. Ekman 2004). Others argue that most emotions persist for about an hour (e.g. Frijda 2007).

14. See, for example, Gino and Schweitzer (2008) for an experiment where emotion manipulation checks were included after the main dependent variable, namely the extent to which participants rely on advice.

15. Such a payoff mechanism avoids wealth and portfolio effects that may emerge if subjects are paid for all decisions either sequentially or at the end of the experiment.

16. Cox et al. (2015) and Harrison and Swarthout (2014) recently reopened the debate on the random lottery incentive mechanism. Cox et al. (2015) show that the only incentive-compatible mechanism under all possible utility specifications is the one task (OT) mechanism, in which each subject responds to-and is paid for-one choice task. Since 'OT allows only for tests of hypotheses using between-subjects data' (Cox et al. 2015, p. 224), it could not be applied to our experiment that intended to use a within-subject design. Additionally, had we considered the possibility of implementing the OT mechanism, this would have required a massive sample size to reach acceptable levels of power and to guarantee random assignment to treatments (Harrison and Swarthout 2014).

17. In a recent article, Drichoutis et al. (2015) manipulate the exchange rate between experimental currency and cash using a private, induced-value second price auction. Their results indicate that the cost of misbehaviour increases with higher induced values. Applied to our setting (where euros, rather than fictitious experimental currencies, are used), this suggests that the relatively large expected earnings, in comparison to a typical student hourly wage, may increase the perceived cost of misbehaviour and the cognitive effort required to make a truthful decision.

18. Recall that in our experiment, $x_{1}=y_{1}=€ 0, x_{2}=y_{2}=€ 8, x_{3}=y_{3}=€ 16$ and $x_{4}=y_{4}=€ 24$.

19. A peculiar aspect of this approach, which is similar to that used by Botti et al. (2008), is that the distribution of the parameter that shapes the weighting function of the RDEU model includes values of that parameter 
that are statistically indistinguishable from 1 (the case in which the RDEU models collapses to the EU model), and in this sense the RDEU model is capable of including both RDEU and EU subjects.

20. From now on, having already made clear which components of the model will be treated as individualspecific, we suppress the subscript $i$.

21. For details on both maximum simulated likelihood techniques and Halton sequences, see Train (2003).

22. We elected to follow a conservative approach (see, for example, Ugazio et al. 2012) and excluded from the sample participants who did not show the expected affective response to the manipulation. For instance, about $30 \%$ of the participants in the anger treatment - who watched the film clip from My Bodyguarddeclared that the clip made them feel sadder rather than angrier. Such participants are not included in the data analysis.

23. The demographics of the full set of participants (including those for whom the emotion induction did not work satisfactorily) mirror those of the considered sample. Also, for the full set of observations we do not detect significant differences in gender, age, major of study and number of previous experiments across treatments ( $p$-values are, respectively, $0.301,0.745,0.123$, and $0.224 ; \mathrm{KW}$ tests). This reassures us that the failure to reject the null hypothesis of no difference between treatments in our reduced sample is not due to its small size (which may determine a low power of the test). Hence we can safely assume that the result of the test for subjects' random assignment to treatments is not due to a type II error.

24. Further details on the construction of the joviality, sadness, fear and anger factors can be found in Watson and Clark (1999). In some sessions, due to a bug in the software, an item for each subject was recorded as a missing value. To undertake a conservative approach, the missing data were treated as zeros.

25. This approach to Likert-scale data preserves the ordinal attributes of the items. Alternative approaches (such as taking, for each item, the difference between Part 1 and Part 2 and then, for each subject, summing these differences for the items in the same emotion) may be seen as more informative. Yet they presume that the intervals between Likert values are equal and give a cardinal interpretation to the scores. For a discussion on the appropriateness of treating Likert responses as absolute (cardinal) measures, see, for example, Jamieson (2004) or Dittrich et al. (2007).

26. All results remain qualitatively the same when one-way ANOVA tests, rather than KW tests, are used. All reported KW tests involve the neutral treatment. Excluding it, the KW p-values are 0.0032 for joviality, 0.0001 for sadness, 0.0247 for fear, and 0.0032 for anger. These results further confirm that the emotion manipulation was successful.

27. Given the relevance of stochastic errors discussed, among others, by Hey (2005) and Loomes (2005), we have also fitted all the specifications under several different modelling approaches, which include (alone and in combination) the contextual utility error specification, introduced by Wilcox $(2008,2011)$, the strict utility model proposed by Luce (1959), and mixture models with an expected utility and a rank dependent component à la Harrison and Rutström (2009). For a recent and comprehensive discussion of the relevant literature on the tested stochastic error specifications and relative modelling details, the reader is referred to Drichoutis and Lusk (2014) and references therein. Here, we have reported only the econometric models and the results from the specification that appears to perform best on our data. Further details are available on request.

28. The maximum likelihood estimates of the preference functionals do not depend on having considered only the 171 subjects who declared to have felt the target emotion. Had we used the observations collected from all 300 subjects, the results would have remained qualitatively unaltered.

29. Had we used a gender dummy and interacted it with all the variables, we would have obtained the same results but the estimated coefficients would have been harder to interpret because of the presence of a large number of interaction coefficients. Additionally, by estimating separate models for males and females, we allow the dispersion of the parameters of interest not to be the same for both subsamples, providing more accurate sample-specific results. The same arguments hold when we split the sample according to subjects' experience.

30. The threshold was set to 6 in order to obtain groups of similar sizes, that is, 6 is the median participation in previous experiments.

\section{REFERENCES}

Andersen, S., Harrison, G., LAU, M. and Rutström, E. (2006). Elicitation using multiple price list formats. Experimental Economics, 9(4), 383-405.

Arkes, H. R., Herren, L. T. and Isen, A. M. (1988). The role of potential loss in the influence of affect on risktaking behavior. Organizational Behavior and Human Decision Processes, 42(2), 181-93.

Azrieli, Y., Chambers, C. P. and Healy, P. J. (2012). Incentives in experiments: a theoretical analysis. Working Paper, Ohio State University.

BeAttie, J. and Loomes, G. (1997). The impact of incentives upon risky choice experiments. Journal of Risk and Uncertainty, 14(2), 155-68.

Bellizzi, J. A. and Hite, R. E. (1992). Environmental color, consumer feelings, and purchase likelihood. Psychology and Marketing, 9(5), 347-63. 
Bosch-Domènech, A. and Silvestre, J. (2013). Measuring risk aversion with lists: a new bias. Theory and Decision, 75(4), 465-96.

Botti, F., Conte, A., Di CAgno, D. T. and D'Ippoliti, C. (2008). Risk attitude in real decision problems. B. E. Journal of Economic Analysis \& Policy, 8(1 (Advances)), article 6.

CAmerer, C. F. and Hogarth, R. M. (1999). The effects of financial incentives in experiments: a review and capital-labor-production framework. Journal of Risk and Uncertainty, 19(1), 7-42.

Charness, G., Gneezy, U. and Imas, A. (2013). Experimental methods: eliciting risk preferences. Journal of Economic Behavior and Organization, 87, 43-51.

—— - - and KUHN, M. A. (2012). Experimental methods: between-subject and within-subject design. Journal of Economic Behavior and Organization, 81(1), 1-8.

Chou, K.-L., LeE, T. M. C. and Ho, A. H. Y. (2007). Does mood state change risk-taking tendency in older adults? Psychology and Aging, 22(2), 310-18.

ChuAng, Y. and Schechter, L. (2015). Stability of experimental and survey measures of risk, time, and social preferences: a review and some new results. Journal of Development Economics, 117, 151-70.

Cimbalo, R. S., Beck, K. L. and Sendziak, D. S. (1978). Emotionally toned pictures and color selection for children and college students. Journal of Genetic Psychology, 133(2), 303-4.

Cox, J. C., Sadiraj, V. and Schmidt, U. (2015). Paradoxes and mechanisms for choice under risk. Experimental Economics, 18(2), 215-50.

Croson, R. and GneEzy, U. (2009). Gender differences in preferences. Journal of Economic Literature, 47(2), 448-74.

Cubitt, R. P., Starmer, C. and Sugden, R. (1998). On the validity of the random lottery incentive system. Experimental Economics, 1(2), 115-31.

Dittrich, R., Francis, B., Hatzinger, R. and Katzenbeisser, W. (2007). A paired comparison approach for the analysis of sets of Likert-scale responses. Statistical Modelling, 7(1), 3-28.

Dohmen, T., Falk, A., Huffman, D., Sunde, U., Schupp, J. and Wagner, G. G. (2011). Individual risk attitudes: measurement, determinants, and behavioral consequences. Journal of the European Economic Association, 9(3), 522-50.

Drichoutis, A. C. and Lusk, J. L. (2014). Judging statistical models of individual decision making under risk using in- and out-of-sample criteria. PLoS ONE, 9(7), e102269.

— - and NAYGA, R. M., Jr (2015). The veil of experimental currency units in second price auctions. Journal of the Economic Science Association, 1(2), 182-96.

_ and NAYGA, R. M., Jr (2013). Eliciting risk and time preferences under induced mood states. Journal of Socio-Economics, 45, 18-27.

Eckel, C. C. and Grossman, P. J. (2008). Men, women and risk aversion: experimental evidence. In C. PlotT and V. SMith (eds), Handbook of Experimental Economics Results, vol. 1. New York: Elsevier, pp. 1061-73.

Ekman, P. (2004). What we become emotional about. In A. S. Manstead, N. Frijda and A. Fischerr (eds), Feelings and Emotions. The Amsterdam Symposium. New York: Cambridge University Press, pp. 119-35.

Fehr-Duda, H., Epper, T., Bruhin, A. and Schubert, R. (2011). Risk and rationality: the effects of mood and decision rules on probability weighting. Journal of Economic Behavior and Organization, 78(1-2), 14-24.

Fessler, D. M., Pillsworth, E. G. and Flamson, T. J. (2004). Angry men and disgusted women: an evolutionary approach to the influence of emotions on risk taking. Organizational Behavior and Human Decision Processes, 95(1), 107-23.

FISCHBACHER, U. (2007). Z-tree: Zurich toolbox for ready-made economic experiments. Experimental Economics, 10(2), 171-8.

Forgas, J. P. (1995). Mood and judgment: the affect infusion model (AIM). Psychological Bulletin, 117(1), 3966.

Friedman, D. and Sunder, S. (1994). Experimental Methods: A Primer for Economists. Cambridge: Cambridge University Press.

FRIJDA, N. H. (2007). The Laws of Emotion. Mahwah, NJ: Lawrence Erlbaum Associates Publishers.

Gino, F. and Schweitzer, M. E. (2008). Blinded by anger or feeling the love: how emotions influence advice taking. Journal of Applied Psychology, 93(5), 1165-73.

Grable, J. E. and Roszkowski, M. J. (2008). The influence of mood on the willingness to take financial risks. Journal of Risk Research, 11(7), 905-23.

Greiner, B. (2004). An online recruitment system for economic experiments. In K. Kremer and V. Macho (eds), Forschung und wissenschaftliches Rechnen 2003. Göttingen: Gesellschaft für Wissenschaftliche Datenverarbeitung, pp. 79-93.

Gross, J. J. and Levenson, R. W. (1995). Emotion elicitation using films. Cognition and Emotion, 9(1), 87-108.

Guiso, L., SAPIEnZA, P. and ZINGALES, L. (2013). Time varying risk aversion. NBERWorking Paper no. 19284. 
HARrison, G. W. (1994). Expected utility theory and the experimentalists. Empirical Economics, 19(2), $223-53$. and Rutström, E. E. (2009). Expected utility theory and prospect theory: one wedding and a decent funeral. Experimental Economics, 12(2), 133-58.

- and Swarthout, J. T. (2014). Experimental payment protocols and the bipolar behaviorist. Theory and Decision, 77(3), 423-38.

Hertwig, R. and Ortmann, A. (2001). Experimental practices in economics: a methodological challenge for psychologists? Behavioral and Brain Sciences, 24(3), 383-403.

Hewig, J., Hagemann, D., Seifert, J., Gollwitzer, M., Naumann, E. and Bartussek, D. (2005). A revised film set for the induction of basic emotions. Cognition and Emotion, 19(7), 1095-109.

HEY, J. D. (2001). Does repetition improve consistency? Experimental Economics, 4(1), 5-54.

(2005). Why we should not be silent about noise. Experimental Economics, 8(4), 325-45.

__ and LEE, J. (2005). Do subjects separate (or are they sophisticated)? Experimental Economics, 8(3), 23365.

Holt, C. A. (1986). Preference reversals and the independence axiom. American Economic Review, 76(3), 50815.

ISEN, A. M. and PATRICK, R. (1983). The effect of positive feelings on risk taking: when the chips are down. Organizational Behavior and Human Performance, 31(2), 194-202.

JAMIESON, S. (2004). Likert scales: how to (ab)use them. Medical Education, 38(12), 1217-18.

JAMison, J., Karlan, D. and Schechter, L. (2008). To deceive or not to deceive: the effect of deception on behavior in future laboratory experiments. Journal of Economic Behavior and Organization, 68(3-4), 477-88.

Kahneman, D. and Tversky, A. (1979). Prospect theory: an analysis of decision under risk. Econometrica, 47 (2), 263-91.

KLIGER, D. and LeVy, O. (2003). Mood-induced variation in risk preferences. Journal of Economic Behavior and Organization, 52(4), 573-84.

Krohne, H. W., Egloff, B., Kohlmann, C.-W. and Tausch, A. (1996). Untersuchungen mit einer deutschen Version der 'Positive and Negative Affect Schedule' (PANAS) (Investigations with a German version of the positive and negative affect schedule (PANAS)). Diagnostica, 42(2), 139-56.

Kugler, T., Connolly, T. and Ordóñez, L. D. (2012). Emotion, decision, and risk: betting on gambles versus betting on people. Journal of Behavioral Decision Making, 25(2), 123-34.

LeE, C. J. and Andrade, E. B. (2011). Fear, social projection, and financial decision making. Journal of Marketing Research, 48(Special Issue), S121-S129.

Lerner, J. S. and Keltner, D. (2001). Fear, anger, and risk. Journal of Personality and Social Psychology, 81 (1), 146-59.

—- Gonzalez, R. M., Small, D. A. and Fischhoff, B. (2003). Effects of fear and anger on perceived risks of terrorism: a national field experiment. Psychological Science, 14(2), 144-50.

emotions on economic decisions. Psychological Science, 15(5), 337-41.

LeVin, I. P., SNyder, M. A. and ChapMAn, D. P. (1988). The interaction of experiential and situational factors and gender in a simulated risky decision-making task. Journal of Psychology, 122(2), 173-81.

LoewensteIn, G. (2000). Emotions in economic theory and economic behavior. American Economic Review, 90 (2), 426-32.

- and Lerner, J. (2003). The role of affect in decision making. In R. Davidson, H. Goldsmith and K. Scherer (eds), Handbook of Affective Science. Oxford: Oxford University Press, pp. 619-42.

Loomes, G. (2005). Modelling the stochastic component of behaviour in experiments: some issues for the interpretation of data. Experimental Economics, 8(4), 301-23.

Luce, R. D. (1959). Individual Choice Behavior: A Theoretical Analysis. New York: Wiley.

PreleC, P. (1998). The probability weighting function. Econometrica, 66(3), 497-527.

Raghunathan, R. and Pham, T. M. (1999). All negative moods are not equal: motivational influences of anxiety and sadness on decision making. Organizational Behavior and Human Decision Processes, 79(1), 56-77.

Robbins, S. P. and Judge, T. A. (2012). Organizational Behavior. Upper Saddle River, NJ: Pearson Prentice Hall.

Röcke, C. and GrüHn, D. (2003). German translation of the PANAS-X. Mimeo, Free University Berlin.

Starmer, C. and Sugden, R. (1991). Does the random-lottery incentive system elicit true preferences? An experimental investigation. American Economic Review, 81(4), 971-8.

Train, K. (2003). Discrete Choice Methods with Simulation. Cambridge: Cambridge University Press.

Treffers, T., Koellinger, P. and Picot, A. (2012). In the mood for risk? A random assignment experiment addressing the effects of moods on risk preferences. ERIM Report Series no. ERS-2012-014-ORG, Erasmus Research Institute of Management. 
Ugazio, G., LAmm, C. and Singer, T. (2012). The role of emotions for moral judgments depends on the type of emotion and moral scenario. Emotion, 12(3), 579-90.

VAN Winden, F., KRAWCZYK, M. and HopfensitZ, A. (2011). Investment, resolution of risk, and the role of affect. Journal of Economic Psychology, 32(6), 918-39.

WATSON, D. and CLARK, L. (1999). The PANAS-X: manual for the positive and negative affect scheduleexpanded form. Iowa Research Online, University of Iowa.

Westermann, R., Spies, K., Stahl, G. and Hesse, F. W. (1996). Relative effectiveness and validity of mood induction procedures: a meta-analysis. European Journal of Social Psychology, 26(4), 557-80.

Wilcox, N. T. (1993). Lottery choice: incentives, complexity and decision time. Economic Journal, 103(421), $1397-417$.

- (2008). Stochastic models for binary discrete choice under risk: a critical primer and econometric comparison. In J. COX and G. HARRISON (eds), Research in Experimental Economics, vol. 12: Risk Aversion in Experiments. Bingley: Emerald, pp. 197-292.

- (2011). 'Stochastically more risk averse:' a contextual theory of stochastic discrete choice under risk. Journal of Econometrics, 162(1), 89-104.

Williams, S., ZAINUBA, M. and JACKSON, R. (2003). Affective influences on risk perceptions and risk intention. Journal of Managerial Psychology, 18(2), 126-37.

YuEN, K. S. and LEE, T. M. (2003). Could mood state affect risk-taking decisions? Journal of Affective Disorders, 75(1), 11-18.

ZHAO, J. (2006). The effects of induced positive and negative emotions on risky decision making. Talk presented at the 28th Annual Psychological Society of Ireland Student Congress, Maynooth, Ireland.

\section{SUPPORTING INFORMATION}

Additional Supporting Information may be found in the online version of this article:

\section{Experimental instructions}

